\title{
Effet du préfanage sur l'utilisation d'un ensilage de balles rondes par des vaches allaitantes
}

\author{
R Berthiaume, C Lafrenière, GL Roy
}

Agriculture et Agro-alimentaire Canada, Ferme de recherche, Kapuskasing, Ontario, P5N 2Y3, Canada

\begin{abstract}
Un essai a été réalisé avec 30 vaches allaitantes afin de déterminer l'effet de la teneur en matière sèche et du mode de stockage sur l'ingestibilité, la digestibilité, les performances animales et les pertes dues à la fermentation. Les trois ensilages récoltés à partir d'une même prairie (1er cycle, dactyle) étaient un ensilage ressuyé à brins courts ( $\mathrm{S}-\mathrm{M}$, silo-meule), un ensilage ressuyé à brins longs ( $B-R$, balles rondes ressuyées) et un ensilage préfané durant 24 heures à brins longs ( $B-P$, balles rondes préfanées). Les balles rondes ont été conservées dans des gaines de plastique.
\end{abstract}

Les vaches et veaux ont été alloués à trois lots comparables de 10 paires en fonction du croisement, de l'âge et du sexe. Chacun d'eux a reçu à volonté l'un des 3 ensilages pendant une période de 91 jours. La seule complémentation était un composé minéral servi en libre choix. L'ingestibilité et la digestibilité des ensilages ont été mesurées sur des bouvillons. Les pertes en silo ont été estimées à partir de sacs enfouis dans le silo pour l'ensilage $S-M$ alors que dans le cas des ensilages B-R et B$P, 1$ balle sur 5 fut choisie au hasard avant d'être pesée et échantillonnée à l'entrée et à la sortie des gaines.

Le préfanage de balles rondes n'a pas eu d'effet significatif bien qu'une très nette tendance à la hausse fut observée surtout au niveau du gain de poids vif $(P=0.079)$ et de l'épaisseur de gras dorsal $(P=0.11)$ des vaches. De plus le préfanage et la forme d'entreposage n'ont pas eu d'effet significatif sur les gains de poids des veaux de même que sur l'ingestibilité et la digestibilité des ensilages. Les pertes dues à la fermentation sont significativement plus faibles $(P=0.015)$ pour l'ensilage B-P comparé à l'ensilage B-R et sont intermédiaires pour l'ensilage S-M.

II semble que le préfanage et le mode de stockage n'exercent qu'un effet mineur sur les performances des vaches allaitantes, du moins si l'ensilage ressuyé est bien conservé. Bien que statistiquement non significatives les tendances observées tendent à démontrer que, pour un même stade de récolte, l'ensilage de balles rondes exige un préfanage ( 24 heures) alors que l'ensilage haché peut être récolté après un léger ressuyage ( \pm 3 heures).
Régime

Gain de poids des vaches $(\mathrm{kg} / \mathrm{j})$

Augmentation de l'épaisseur du

gras dorsal des vaches $(\mathrm{mm})$

Modification d'état corporel

des vaches

Gain de poids des veaux $(\mathrm{kg} / \mathrm{j})$

\section{S-M}

0,24

1,97

0,01

1,11
B-R

0,24

0,51

$-0,07$

1,02
B-P

0,50

2,62

0,18

1,09 